\title{
sciendo Multi-criteria decision method for choosing ERP cloud systems in Industry 4.0 era
}

doi:10.2478/mape-2019-0044

Date of submission to the Editor: 04/2018

Date of acceptance by the Editor: 07/2018

MAPE 2019, volume 2, issue 1, pp. 435-446

\section{Witold Torbacki*}

ORCID ID: 0000-0001-9924-0431

Maritime University of Szczecin, Poland

\section{INTRODUCTION}

In the current era of digital transformation and the concept of Industry 4.0 (Frank et al., 2019) or (Zhong et al., 2017), information about the benefits of transferring IT solutions to cloud computing is constantly being directed towards manufacturing companies. It may seem that it is simply a replacement of the popular purchase model with long-term rental, which is becoming more and more popular also in other sectors (machine and automotive industries). However, it is worth considering whether this model will indeed be the best in each case if an ERP system is used to manage manufacturing companies.

In the case of popular, mass IT solutions (even Microsoft Office), it really is so. There is a distinct difference between a license solution (single purchase) and the SaaS (monthly subscription fee). The main difference concerns a set of available applications and services as well as the flexibility in their selection. In the SaaS model, almost all services offered by Microsoft are available, the possibility to freely select individual applications, and above all, automatic software updates. In the segment of mass IT solutions, the superiority of the cloud version is virtually unquestionable. However, with regard to ERP solutions, the situation looks completely different. Although the majority of software producers have in their offer, apart from the license model, also their systems in the SaaS version, however, this model should not be approached uncritically. ERP systems are not mass solutions, in the majority of cases they are 'tailor-made'. The possibility of extending the standard functionality of an ERP system very often determines the success of its implementation.

The specificity of functioning of companies, even within the same industry, causes that a solution working effectively in one company can even disrupt the functioning of another company. In view of the extensive market offer of ERP cloud systems, a manufacturing company, when selecting a new solution, may not pay attention to the essential elements that determine the success of implementation. Managing staff of manufacturing companies presently pay much attention to the methods of building a market advantage, with the application of IT systems that support the concept of Industry 4.0. While doing that, companies have big problems with choosing a modern ERP system. Given the abundance of the market offer, it may seem that the choice really is between the same or very similar elements. In this article, a number of KPI

\footnotetext{
*w.torbacki@am.szczecin.pl
} 
parameters were formulated to evaluate an ERP cloud system. The KPI parameters were then analyzed using the DEMATEL methodology (Ferreira et al., 2019) or (Gigovic et al., 2016). The importance of individual parameters and a network of interrelations were established. Thanks to this, the article is a kind of compendium of information that can be used as a guide enabling effective selection of a modern ERP cloud solution for manufacturing companies that want to implement Industry 4.0 solutions.

\section{INDUSTRY 4.0 AND ERP SYSTEMS}

The first industrial revolution was connected with the use of steam engines in the production. The second revolution was the period of introducing mass production. A characteristic feature of the third revolution was the automation of production using computers. The term Industry 4.0 is often used to describe the changes related to the fourth industrial revolution. The concept of Industry 4.0 involves comprehensive participation of modern technologies that change the modern industry. These include, among others (Parvin et al., 2013, Liao et al., 2017) or (Nolin and Olson, 2016), the Internet of things, the Internet of services, ERP cloud systems, intelligent factories, artificial intelligence, intelligent production, robotics, digital transformation, augmented reality, man-machine interfaces, as well as cyber-physical systems. An essential element combining these solutions within Industry 4.0 is the widespread use of the Internet in operational work.

Until recently, solutions related to Industry 4.0 were available only to the largest enterprises. Currently, some of them are also available for companies from the SME sector. Companies are often not willing to pay large, single amounts to buy IT systems licenses. The simultaneous development and decapitalisation of IT equipment and systems are so fast that companies are increasingly reaching for the SaaS cloud model, which provides access to the latest ERP systems while maintaining at the same time the total Cost of Ownership (TCO) at a low level.

The actual cycle of activities in an ERP comprising integration of orders, production and distribution of goods within Industry 4.0 may be diverse and tailored to the specificity of the company. It is characterized by comprehensive use of the Internet of things, the Internet of services, and cyber-physical systems for monitoring, optimization and initiation of processes. In the production cycle, this means that IT systems register and monitor the course of physical processes, which, in the feedback loop, affect the process of data processing in the systems.

An example of a workflow in an ERP system related to production may include the following steps (Fig. 1):

- Sales activities (1) as a result of which a production order is placed (2) (through the sales department of the company, or independently by the client using various Internet platforms). In relation to Industry 4.0, this means that also the stock of goods in the store, the recipient's warehouse registered using cyber-physical systems can start a production process. Integration between the modules means that the system creates mutually interrelated sales and stock-keeping documents and orders for missing items to contractors. The graphic WiFi symbol (Fig. 1) means data logging using cyber-physical systems and the transmission of collected data.

- Production preparation (3) with the reservation of hardware, human and material resources. 
- Determining the object of production with the procedures for particular production stages.

- Generation of electronic work cards. Traditional, printed work cards are prepared for the purposes of personal production stations not equipped with computer devices such a hybrid approach also occurs in the case of the so-called smart factories.

- A specific production order is created based on the order placed for production, including, among others, a production schedule, the number and type of product and resources. Created products can be assigned to individual recipients.

- Confirmation of an order for production results in automatic ordering of the missing and necessary components from contractors (4). Automatic ordering of the missing goods and blocking them in the warehouse for the purpose of a specific production order makes it easier to avoid exceeding deadlines and occurrence of the so-called 'bottlenecks'.

- On the basis of a production order and work cards, products are taken from the warehouse and production is started (5).

- Production systems support planning processes based on the analysis of the circulation of products and data registered by cyber-physical systems.

- Ready products are placed in the warehouse.

- After the production is finished, the order is closed and settled in the accounts. Integration between the modules enables automatic settlement of production and obtaining instant information on the financial result of production.

- The systems usually control the actual working time of employees as well as of the implementation of the production order. Thanks to this, it is possible to verify the plan for the execution of tasks, and thus to make the order costs more realistic.

- Products are distributed to clients (6), and in ERP systems, they are covered by service and complaint processes (7).

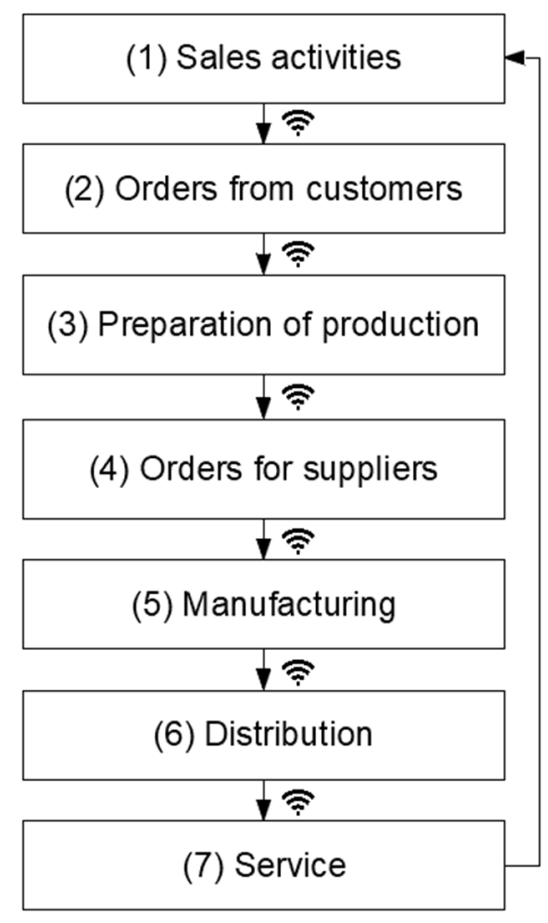

Fig. 1 The processing of orders, production and distribution in an ERP system (space) 


\section{PARAMETERS OF THE ERP CLOUD SYSTEM ASSESSMENT IN THE CONCEPT OF INDUSTRY 4.0}

Knowledge of reliable indicators of the quality assessment of the SaaS services is necessary for the correct selection of the solution provider in this mode. For software producers, the transition from the traditional, licensed way of software distribution to the cloud model means the possibility of maintaining the continuity of revenues and finding new markets in the changing situation on the IT market. In order to provide SaaS services to clients, companies must either maintain their own Data Centers or rent them from providers of complete IT platforms in the Infrastructure as a Service (laaS) model or the Platform as a Service (PaaS) model (Naren et al., 2014). In any case, SaaS providers have to bear the additional costs of their activity, which, of course, they want to minimize while at the same time maintaining the satisfying level of service for clients. The SaaS service user should be aware of this and choosing the service, on the one hand, they should select the IT system with the desired functionality, and on the other hand, choose a solution provider that guarantees a sufficiently high level of service. Below, a set of $11 \mathrm{KPI}$ parameters is proposed, which should be taken into account when selecting an ERP cloud solution for a manufacturing company (Table 1).

It should be remembered that the current promotion of ERP cloud systems as the best solution for every modern manufacturing company, is often just an empty marketing slogan that takes advantage of the current popularity of the cloud model. The decision whether the system should be rented in the cloud or in the license mode should be one of the last stages of the software selection process. Therefore, the choice of the system based on this criterion (SaaS or license) in practice means the wrong start of the whole process exactly from the end. The correct order should cover issues related to the choice of the system functions and the possibilities of its adaptation to the specificity of the company (perspective $C$ in Table 1). The choice of architecture (perspective A) and of the implementation process (perspective $M$ ) should be taken only in the next step.

Table 1

Parameters of the choice and evaluation of an ERP cloud system

\begin{tabular}{|c|c|c|}
\hline Perspective & KPI & Description \\
\hline \multirow{4}{*}{$\begin{array}{l}\text { Choice and adaptation of the } \\
\text { system (C) }\end{array}$} & $\mathrm{C} 1$ & System development plans \\
\hline & $\mathrm{C} 2$ & Market history of the system \\
\hline & C3 & References of the SaaS service provider \\
\hline & $\mathrm{C} 4$ & Adaptation of the system to the recipient's industry \\
\hline \multirow{4}{*}{ System architecture (A) } & A1 & Offline operation of the system \\
\hline & A2 & Costs and type of contract \\
\hline & A3 & Technologies applied in the system \\
\hline & A4 & Data security \\
\hline \multirow{3}{*}{ System implementation (M) } & M1 & Implementation partner \\
\hline & M2 & Data export and import \\
\hline & M3 & Service Level Agreements \\
\hline
\end{tabular}

System development plans (C1). It is worth following the information published by the service provider about the changes in the software in a selected period of time and possible publications about the directions of planned development. Thanks to this, it is possible to obtain confirmation of the software's adaptation to own needs and to verify the flexibility of the producer and its speed of reaction to the changing requirements of the market. 
Market history of the system (C2). The majority of ERP solutions present on the market were created for the traditional licensing model of software distribution via optical media and off-line operation. In some of them, on-line operation was made available, as well as some of them were adapted for mobile operation on mobile devices. However, the original architecture of such solutions is often not suited to the management of the distributed structure of companies and does not provide recipients with all the possible advantages of modern IT systems. Only the use of a comprehensive software development strategy, designed in advance for the SaaS market, can ensure the implementation of an IT system that will meet with the favorable perception of the market.

References of the SaaS service provider (C3). It is necessary to ask for a reference list and examples of interesting implementations. The most valuable would be to get feedback from the companies that have used the software for a long time and from those which have given up its rental. It is also worth examining the company's stability and financial transparency. It may be difficult but worthwhile to obtain valuable information about the qualifications of persons responsible for the company management and software development, in particular from the analysis and research and development departments.

Adaptation of the system to the recipient's industry (C4). Although most software providers claim that their applications meet the needs of companies from different industries, in practice, you should approach statements of this type with caution. Before the purchase, it is important to verify whether the existing client base contains a sufficient number of companies similar to the profile of the future client. This will also ensure that in the future the requirements of this type of companies regarding the development of functionality will be taken seriously in the production plans of subsequent versions. The software should be selected with the participation of an external implementation partner.

Off-line operation of the system (A1). In the case of a cloud system, the company must have access to the Internet and a redundant internet connection that will ensure the stability of the network. The Internet connection must be efficient in order to handle all required processes optimally. It is necessary to check whether the system is able to operate offline, in the event of interruptions in access to the Internet. This is extremely important for manufacturing companies with continuous mobility. On the other hand, also individual production workplaces may be without Internet access or even they may not be designed for operation with the use of electronic devices.

Costs and type of contract (A2). Attention should be paid to the type of rental contract, its minimum duration, the mode of contract termination, special clauses, the total costs of implementation, training and data transfer. Another issue is to compare the prices of different solutions, which, often under similar names, cover not fully identical functionalities. It is important to verify whether a software upgrade is provided as part of subscription fees.

Technologies applied in the system (A3). It is necessary to get an idea of what software tools have been used to create the software, what platforms the software is designed for, and on what devices it can be launched at present and in the future. The technologies used by the system creator should be verified in terms of ensuring scalability of the solution, redundancy of infrastructure and reliability of the solution. When choosing ERP systems in the SaaS, it is worth remembering to pay attention 
to the producer's recommendations regarding operation in particular browsers and on various devices, especially mobile devices such as smartphones and tablets.

Data security (A4). Data about contractors are often a huge value of enterprises. In the SaaS model, it is always necessary to estimate the risk of data loss or, which is equally dangerous, a takeover by the competition. It is necessary to check the security procedures implemented by the service provider. It is also necessary to determine the backup Data Centers of a service provider, which should ensure that in the event of a failure of the main center, the processing will be immediately taken over by the backup centers. It is also necessary to check how the data is protected on the part of the user and their workstation.

Implementation partner (M1). It is necessary to verify whether there are implementation partners on the market, independent of the software provider, which can carry out the implementation process. It is important if they have experience in implementing the pre-selected cloud software in companies from a similar industry.

Data export and import (M2). The client should have the possibility to export data and to have access to archived data. Companies may want to withdraw from the SaaS model. In this case, it is important to be able to export data to new systems. In other cases, such as the suspension of a company's activity, bankruptcy or due to a tax audit or a lawsuit, it may necessary to access the archived data. It is important to check whether the provider has taken such situations into account, and whether relevant procedures have been prepared in this regard.

Service Level Agreements (M3). SLA usually means a contract under which the service provider defines a minimum, guaranteed and measurable level of services offered, the violation of which often results in payment of compensation. The parameters included in the contract guarantee that the service recipient shall obtain high performance, availability and data security. Special significance in the SLA contract is given to the statistics of the quality of services provided. The measurement of work parameters by the service provider should be continuous and the results should be easily available for verification by the service recipient.

\section{DEMATEL METHOD}

Multi-criteria decision analysis (MCDA) is often used to model and assess the validity and interrelations between individual parameters for various purposes. DEMATEL technique (Gabus, 1972) or (Si et al., 2018) is one of MCDA method. It is a useful method to analyse the interdependent relationships among coefficients in a complex system and rank them for strategic decision and indicating improvement directions. In this article, DEMATEL method is used to identify a correlation between sets of KPIs for modern cloud ERP systems which help companies to gain Industry 4.0 principles. DEMATEL method converts the interrelations between KPIs to the simple structural model of the system. It divides them into a reason group and an effect group. The DEMATEL technique is summarised in eight steps, given as follows.

Step 1 . In the beginning, a list of $k$ parameters, which will undergo the analysis, must be done.

Step 2. A group of $n$ experts was established. Each of them was asked to indicate the direct influence between different factors, using a numeric scale which goes from 0 (no influence) to 4 (very high influence). Then the values of mutual interactions within pairs of all the criteria were determined. It was assumed that each of the $k$ 
factors may directly influence another factor, but it cannot influence itself. Finally, $n$ partitive initial direct influence matrices $\boldsymbol{Z}_{m}$ were created by each $m$-th expert:

$$
\boldsymbol{Z}_{m}=\left[z_{i j}^{m}\right]_{k \times k}
$$

where all principal diagonal elements are equal to zero and $z_{i j}^{m}$ represents the assessment provided by the $m$-th expert regarding the degree to which parameter $i$ influences parameter $j$. In this way, a set of partial matrices was obtained.

Step 3. Aggregation of these matrices resulted in direct influence matrix $\boldsymbol{Z}=\left[z_{i j}\right]_{k \times k}$ which can be obtained by

$$
\boldsymbol{Z}=\frac{1}{n} \sum_{m=1}^{n}\left[z_{i j}^{m}\right], i, j=1,2,3, \ldots k
$$

Step 4. Normalized direct influence matrix $\boldsymbol{X}$ can be determined by using equations (3)-(4).

$$
\boldsymbol{X}=\left[x_{i j}\right]_{k \times k}=\frac{\boldsymbol{Z}}{\boldsymbol{S}}
$$

where:

$$
s=\max \left(\max _{1 \leq i \leq k} \sum_{j=1}^{k} z_{i j}, \max _{1 \leq j \leq k} \sum_{i=1}^{k} z_{i j}\right)
$$

Step 5. Matrix of total relations $\boldsymbol{T}=\left[t_{i j}\right]_{k \times k}$ was derived by

$$
\boldsymbol{T}=\boldsymbol{X}(\boldsymbol{I}-\boldsymbol{X})^{-1}
$$

where:

$I$ is an identity matrix.

Step 6. The vectors $\boldsymbol{C}$ and $\boldsymbol{R}$ representing the sum of the of the columns and the sum of the rows from the matrix $\boldsymbol{T}$ can be obtained by

and

$$
\boldsymbol{C}=\left[c_{j}\right]_{1 \times k}=\left[\sum_{j=1}^{k} t_{i j}\right]_{1 \times k}^{T}
$$

where:

$c_{j}$ is the $j$-th column sum in the matrix $\boldsymbol{T}$.

It reflects the whole direct and indirect effects that parameter $j$ is receiving from all the other ones. Likewise, $r_{i}$ is the $i$-th row sum in the matrix $\boldsymbol{T}$. It mirrors the sum of direct and indirect effects dispatching from parameter $i$ to the other ones.

Let $i=j$ and $i, j \in\{1,2, \ldots, k\}$, a 'relation' indicator $r_{i}-c_{j}$ was derived. It is also called a net influence. The vertical 'relation' axis vector $\boldsymbol{R}-\boldsymbol{C}$ reflects the net effect that the factor contributes to the whole system. Similarly, a 'position' indicator $r_{i}+c_{j}$ was obtained, which reflects an overall influence (which both influence the other criteria and are under the influence of other criteria). The horizontal 'position' axis $\boldsymbol{R}+$ $\boldsymbol{C}$ illustrates the strength of influences that are received and given of the indicator. It means $\boldsymbol{R}+\boldsymbol{C}$ reflects the degree of the central role that the factor plays in the entire analysed system. 
When it comes to $\boldsymbol{R}-\boldsymbol{C}$, the value of $r_{i}-c_{j}>0$ means that criterion $i$ influences other criteria as well as the entire system. The value $r_{i}-c_{j}<0$ stands for that other criteria influence criterion $i$. That is why, criterion $i$ is not a source of impact on the rest of criteria in the analysed system.

Step 7. Based on $\boldsymbol{T}=\left[t_{i j}\right]_{k \times k}$ matrix, the influential relation diagram in the $\left(r_{i}+c_{j}, r_{i}-c_{j}\right)$ layout can be plotted, using $r_{i}+c_{j}$ as the horizontal axis and $r_{i}-c_{j}$ as the vertical axis. As a result of the analysing the values of $r_{i}-c_{j}$ and $r_{i}+c_{j}$ indicators, DEMATEL analysis determines the level of correlations of the criteria as well as the criteria which influence other criteria. On the other hand, this method settles the criteria which depend on other criteria as well as are the receivers of influence of other criteria.

Step 8. The analysis of each of criteria on the influential relation diagram should be done. The position of each criterion in the diagram gives information about which criteria have a great impact on other ones or have a complex relationship with other criteria.

\section{CASE STUDY - ERP CLOUD SYSTEM}

In order to appoint the parameters shown in Table 1, seven expert interviews were executed. The experts had deep knowledge in both the ERP cloud systems and area of manufacturing, especially in the Industry 4.0 context. They established three perspectives and the set of eleven criteria presented in Table 1. These parameters should be a guide in the process of choosing a new ERP system. The experts assessed interactions between pairs of all the criteria. They used a 5-grade scale (from 0 - no influence to 4 - very high influence). Based on their assessments, seven partitive initial direct influence matrices $\boldsymbol{Z}_{m}$ were received, see equation (1). Superposition of the matrices, in accordance with equation (2), gave direct influence matrix $\boldsymbol{Z}$ (Table 2).

Table 2

Direct influence matrix $Z$

\begin{tabular}{|c|c|c|c|c|c|c|c|c|c|c|c|}
\hline$Z$ & $\mathbf{C 1}$ & $\mathbf{C 2}$ & $\mathbf{C 3}$ & $\mathbf{C 4}$ & $\mathbf{A 1}$ & $\mathbf{A 2}$ & $\mathbf{A 3}$ & $\mathbf{A 4}$ & $\mathbf{M 1}$ & M2 & M3 \\
\hline C1 & 0 & 0.857 & 1.571 & 3.286 & 2.714 & 3.143 & 1.714 & 3.143 & 0.714 & 1.857 & 1.286 \\
\hline C2 & 0.714 & 0 & 1.857 & 3.143 & 2.143 & 3.429 & 1.286 & 2.857 & 0.857 & 2.714 & 1.857 \\
\hline C3 & 1.857 & 1.714 & 0 & 3.429 & 2.286 & 3.857 & 1.429 & 2.857 & 1.286 & 1.714 & 2.143 \\
\hline C4 & 2.286 & 1.857 & 1.714 & 0 & 2.143 & 3.429 & 1.143 & 3.571 & 1.143 & 1.714 & 1.571 \\
\hline A1 & 1.571 & 1.286 & 1.857 & 3.143 & 0 & 2.857 & 1.857 & 2.857 & 2.286 & 3.143 & 3.286 \\
\hline A2 & 2.571 & 2.429 & 2.429 & 3.857 & 2.714 & 0 & 3.143 & 3.714 & 1.714 & 2.429 & 1.571 \\
\hline A3 & 1.714 & 1.286 & 2.571 & 2.286 & 2.143 & 2.714 & 0 & 3.143 & 1.571 & 2.286 & 2.714 \\
\hline A4 & 2.286 & 2.571 & 2.714 & 3.286 & 2.857 & 3.571 & 3.286 & 0 & 1.571 & 2.857 & 1.857 \\
\hline M1 & 1.143 & 1.286 & 1.571 & 2.429 & 1.857 & 2.429 & 1.714 & 2.714 & 0 & 3.143 & 1.143 \\
\hline M2 & 1.714 & 1.286 & 2.429 & 2.857 & 3.143 & 2.571 & 2.714 & 3.143 & 1.714 & 0 & 2.571 \\
\hline M3 & 1.857 & 1.143 & 2.143 & 3.143 & 2.143 & 2.714 & 2.857 & 3.143 & 2.143 & 2.429 & 0 \\
\hline
\end{tabular}


Further on, based on equation (3), normalized direct influence matrix $\boldsymbol{X}$ (Table 3) was determined.

Table 3

Normalized direct influence matrix $X$

\begin{tabular}{|c|c|c|c|c|c|c|c|c|c|c|c|}
\hline$X$ & $\mathbf{C 1}$ & $\mathbf{C 2}$ & $\mathbf{C 3}$ & $\mathbf{C 4}$ & $\mathbf{A 1}$ & $\mathbf{A 2}$ & $\mathbf{A 3}$ & $\mathbf{A 4}$ & M1 & M2 & M3 \\
\hline C1 & 0 & 0.028 & 0.050 & 0.106 & 0.087 & 0.101 & 0.055 & 0.101 & 0.023 & 0.060 & 0.041 \\
\hline C2 & 0.023 & 0 & 0.060 & 0.101 & 0.069 & 0.110 & 0.041 & 0.092 & 0.028 & 0.087 & 0.060 \\
\hline C3 & 0.060 & 0.055 & 0 & 0.110 & 0.073 & 0.124 & 0.046 & 0.092 & 0.041 & 0.055 & 0.069 \\
\hline C4 & 0.073 & 0.060 & 0.055 & 0 & 0.069 & 0.110 & 0.037 & 0.115 & 0.037 & 0.055 & 0.050 \\
\hline A1 & 0.050 & 0.041 & 0.060 & 0.101 & 0 & 0.092 & 0.060 & 0.092 & 0.073 & 0.101 & 0.106 \\
\hline A2 & 0.083 & 0.078 & 0.078 & 0.124 & 0.087 & 0 & 0.101 & 0.119 & 0.055 & 0.078 & 0.050 \\
\hline A3 & 0.055 & 0.041 & 0.083 & 0.073 & 0.069 & 0.087 & 0 & 0.101 & 0.050 & 0.073 & 0.087 \\
\hline A4 & 0.073 & 0.083 & 0.087 & 0.106 & 0.092 & 0.115 & 0.106 & 0 & 0.050 & 0.092 & 0.060 \\
\hline M1 & 0.037 & 0.041 & 0.050 & 0.078 & 0.060 & 0.078 & 0.055 & 0.087 & 0 & 0.101 & 0.037 \\
\hline M2 & 0.055 & 0.041 & 0.078 & 0.092 & 0.101 & 0.083 & 0.087 & 0.101 & 0.055 & 0 & 0.083 \\
\hline M3 & 0.060 & 0.037 & 0.069 & 0.101 & 0.069 & 0.087 & 0.092 & 0.101 & 0.069 & 0.078 & 0 \\
\hline
\end{tabular}

In accordance with equation (5), matrix of total relations $\boldsymbol{T}$ (Table 4) was computed.

Table 4

The matrix of total relations $T$

\begin{tabular}{|c|c|c|c|c|c|c|c|c|c|c|c|}
\hline $\boldsymbol{T}$ & $\mathbf{C 1}$ & $\mathbf{C 2}$ & $\mathbf{C 3}$ & $\mathbf{C 4}$ & $\mathbf{A 1}$ & $\mathbf{A 2}$ & $\mathbf{A 3}$ & $\mathbf{A 4}$ & $\mathbf{M 1}$ & M2 & M3 \\
\hline C1 & 0.149 & 0.160 & 0.215 & 0.334 & 0.271 & 0.328 & 0.224 & 0.332 & 0.145 & 0.243 & 0.199 \\
\hline C2 & 0.176 & 0.137 & 0.228 & 0.337 & 0.260 & 0.343 & 0.217 & 0.331 & 0.153 & 0.272 & 0.219 \\
\hline C3 & 0.219 & 0.198 & 0.183 & 0.362 & 0.278 & 0.372 & 0.232 & 0.349 & 0.173 & 0.257 & 0.237 \\
\hline C4 & 0.218 & 0.191 & 0.221 & 0.242 & 0.258 & 0.340 & 0.211 & 0.347 & 0.158 & 0.242 & 0.208 \\
\hline A1 & 0.220 & 0.193 & 0.251 & 0.369 & 0.222 & 0.358 & 0.257 & 0.364 & 0.211 & 0.311 & 0.281 \\
\hline A2 & 0.263 & 0.239 & 0.284 & 0.412 & 0.321 & 0.300 & 0.307 & 0.411 & 0.205 & 0.309 & 0.249 \\
\hline A3 & 0.214 & 0.184 & 0.259 & 0.328 & 0.272 & 0.338 & 0.188 & 0.354 & 0.182 & 0.273 & 0.254 \\
\hline A4 & 0.257 & 0.245 & 0.294 & 0.401 & 0.328 & 0.406 & 0.314 & 0.308 & 0.203 & 0.324 & 0.260 \\
\hline M1 & 0.176 & 0.166 & 0.208 & 0.298 & 0.238 & 0.296 & 0.216 & 0.309 & 0.116 & 0.271 & 0.187 \\
\hline M2 & 0.224 & 0.193 & 0.267 & 0.361 & 0.314 & 0.351 & 0.280 & 0.372 & 0.195 & 0.219 & 0.263 \\
\hline M3 & 0.225 & 0.186 & 0.256 & 0.363 & 0.282 & 0.350 & 0.280 & 0.367 & 0.204 & 0.286 & 0.181 \\
\hline
\end{tabular}

Matrix of total relations $\boldsymbol{T}$ can be considered as a set of two submatrices. First one is submatrix $\boldsymbol{T}_{\boldsymbol{P}}$ based on the three perspectives given in Table 1, the second one is submatrix $\boldsymbol{T}_{\boldsymbol{K}}$ based on eleven KPIs. Table 5 presents submatrices $\boldsymbol{T}_{\boldsymbol{P}}$ and $\boldsymbol{T}_{\boldsymbol{K}}$ and respective indicators $r_{i}$ and $c_{i}$ determined by equations (6-7) as well as 'relation' indicators $r_{i}-c_{i}$ and 'position' indicators $r_{i}+c_{i}$. 
Table 5

The $T_{P}$ and $T_{K}$ submatrices and related indicators

\begin{tabular}{|c|c|c|c|c|c|c|c|c|c|}
\hline$T_{P}$ & $r_{i}$ & $c_{i}$ & $r_{i}+c_{i}$ & $r_{i}-c_{i}$ & $T_{K}$ & $r_{i}$ & $c_{i}$ & $r_{i}+c_{i}$ & $r_{i}-c_{i}$ \\
\hline \multirow{4}{*}{ C } & \multirow{4}{*}{0.725} & \multirow{4}{*}{0.743} & \multirow{4}{*}{1.468} & \multirow{4}{*}{-0.017} & C1 & 2.600 & 2.342 & 4.942 & 0.259 \\
\hline & & & & & $\mathrm{C} 2$ & 2.673 & 2.091 & 4.765 & 0.582 \\
\hline & & & & & C3 & 2.861 & 2.666 & 5.527 & 0.195 \\
\hline & & & & & C4 & 2.637 & 3.808 & 6.445 & $-1,171$ \\
\hline \multirow{4}{*}{ A } & \multirow{4}{*}{0.846} & \multirow{4}{*}{0.914} & \multirow{4}{*}{1.760} & \multirow{4}{*}{-0.067} & $\mathrm{~A} 1$ & 3.036 & 3.045 & 6.081 & -0.009 \\
\hline & & & & & A2 & 3.300 & 3.781 & 7.082 & -0.481 \\
\hline & & & & & A3 & 2.845 & 2.727 & 5.572 & 0.118 \\
\hline & & & & & A4 & 3.341 & 3.844 & 7.185 & -0.504 \\
\hline \multirow{3}{*}{$\mathbf{M}$} & \multirow{3}{*}{0.762} & \multirow{3}{*}{0.678} & \multirow{3}{*}{1.440} & \multirow{3}{*}{0.084} & M1 & 2.482 & 1.946 & 4.428 & 0.536 \\
\hline & & & & & M2 & 3.040 & 3.008 & 6.048 & 0.033 \\
\hline & & & & & M3 & 2.980 & 2.538 & 5.518 & 0.442 \\
\hline
\end{tabular}

In reference to submatrix $\boldsymbol{T}_{\boldsymbol{P}}$ the influential relation diagram can be created (Figure 2) for three perspectives from Table 1.

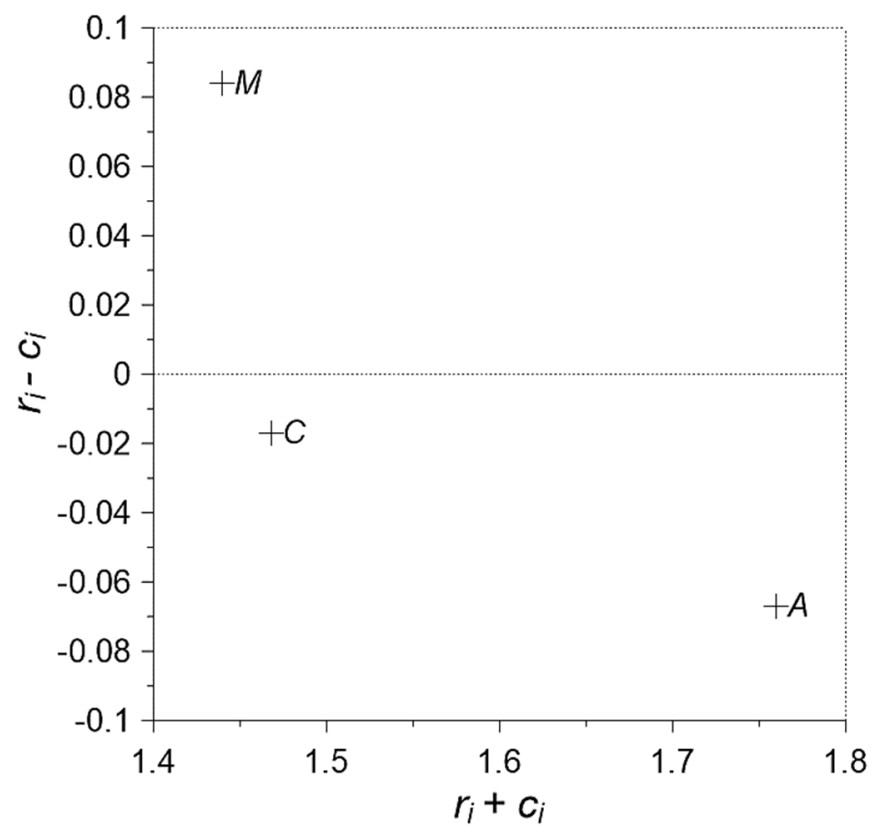

Fig. 2 Influential relation diagram for three perspectives in cloud ERP systems

In Fig. 2, perspective A - System architecture has the highest value of 'position' indicator $r_{i}+c_{i}$. It means that it is the most strongly interconnected with the other perspectives, taking up the central position in the network of interconnections. Perspective $\mathrm{M}$ - System implementation shows the lowest level of this indicator.

The 'relation' indicator $r_{i}-c_{i}$ gives the possibility to establish the influence of the analysed parameter on the other KPIs. It is thought that it gives a possibility to reflect the parameter priority among the others. In Fig. 2, perspective Perspective M System implementation shows the highest positive value of the 'relation' indicator $r_{i}-$ $c_{i}$. It means that this perspective has a major, causative impact on the other perspectives. Parallel, it is the most important out of the presented three perspectives. In Figure 3 the influential relation diagram for eleven chosen KPI criteria in ERP cloud is presented. 


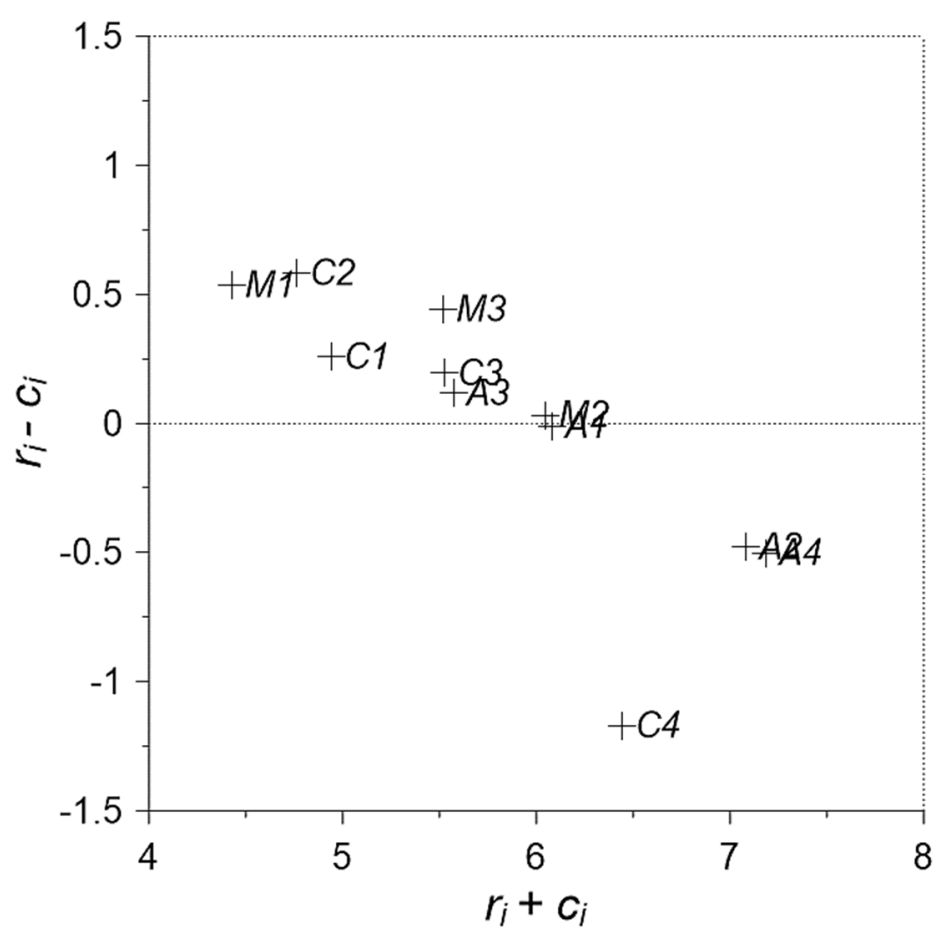

Fig. 3 Influential relation diagram for eleven criteria in cloud ERP systems

In Fig. 3, the highest value of the 'position' indicator $r_{i}+c_{i}$ has A4 - Data security, from perspective $A$ - System architecture, on this account taking up the privileged important position in comparison with the others. Criterion M1 - Implementation partner has the lowest value of this indicator. On the other hand, criterion C2 - Market history of the system, from perspective $\mathrm{C}$ - Choice and adaptation of the system, with the highest positive value of the 'relation' indicator $r_{i}-c_{i}$ gives the strongest impact on the other criteria and is the most crucial criterion in the process of assessment and choosing of ERP cloud systems for companies connected with production processes under the Industry 4.0 concept. At the same time, criterion C4 - Adaptation of the system to the recipient's industry, with the highest negative value of this indicator, is the biggest receiver of impact used by the others.

\section{CONCLUSION}

The state-of-the-art Industry 4.0 concept is currently changing related production processes. To achieve the principles connected with this idea, enterprises need to have the appropriate software. One of the solutions from this area is software in the cloud IT. The article concentrates on the analysis of a set of characteristic features connected with ERP cloud systems.

In the article, within the framework of three perspectives, eleven specific KPIs were assumed. The reciprocal impact matrices for all pairs of KPIs were specified. Moreover, the DEMATEL method was applied to obtain the direct-indirect influence matrix of total relations $T$, which was used to create the corresponding impact-relation diagram. The 'relation' and 'position' indicators were received for three perspectives as well as for eleven KPIs. Perspectives and KPIs both with the highest and the lowest influence effect were established. They should be treated as guide points during the process of choosing a ERP cloud system. 


\section{ACKNOWLEDGEMENTS}

The results of the research studies presented in this article were accomplished as part of the research project 1/S/PUBL/WIET/2018 financed from the grant of the Ministry of Science and Higher Education to finance statutory activities.

\section{REFEENCES}

Ferreira, F.A.F., Ilander, G.O.P.-B. and Ferreira, J.J.M. (2019). MCDM/A in practice: methodological developments and real-world applications. Management Decision, 57(2), pp. 295-299.

Frank, A.G., Dalenogare, S.L. and Ayala, N.F. (2019). Industry 4.0 technologies: Implementation patterns in manufacturing companies. International Journal of Production Economics, 210, pp. 15-26.

Gabus, A. and Fontela, E. (1972). World problems, an invitation to further thought within the framework of DEMATEL. Geneva: Battelle Geneva Research Center.

Gigovic, L., Pamučar, D., Lukic, D. and Markovic, S. (2016). GIS-Fuzzy DEMATEL MCDA model for the evaluation of the sites for ecotourism development: A case study of "Dunayski kljuc" region, Serbia. Land Use Policy, 58, pp. 348-365.

Liao, Y., Deschamps, F., Loures, E.F.R. and Ramos, L.F.P. (2017). Past, Present and Future of Industry 4.0 - a Systematic Literature Review and Research Agenda Proposal. International Journal of Production Research, 55(12), pp. 3609-3629.

Naren, J., Sowmya, S.K. and Deepika, P. (2014). Layers of Cloud - laaS, PaaS and SaaS: A Survey. International Journal of Computer Science and Information Technology, 5(3), pp. 4477-4480.

Nolin, J. and Olson, N. (2016). The internet of things and convenience. Internet Research, 26(2), pp. 360-376.

Parvin, S., Hussain, F., Hussain, O., Thein, T. and Park, J. (2013). Multi-cyber framework for availability enhancement of cyber-physical systems. Computing, 95(10-11), pp. 927948.

Si, S.-L., You, X.-Y., Liu, H.-C. and Zhang, P. (2018). DEMATEL Technique: A Systematic Review of the State-of-the-Art Literature on Methodologies and Applications. Mathematical Problems in Engineering, 3696457, pp. 1-33.

Zhong, R.Y., Xu, X., Klotz, E. and Newman, S.T. (2017). Intelligent Manufacturing in the Context of Industry 4.0: A Review. Engineering, 3(5), pp. 616-630.

Abstract. The article presents the issues covering the modern ERP cloud systems for manufacturing companies within the currently developed concept Industry 4.0. In this approach, research problems arose as to which parameters and characteristics of ERP cloud systems are the most important from the point of view of manufacturing companies as well as how the process of choosing an ERP system should be conducted. In addition, mutual relationships between these parameters were established. In the article, a multi-criteria decision analysis (MCDA) was used to assess these characteristics. The Decision making trial and evaluation laboratory (DEMATEL) technique was chosen for this assessment. The article can be useful to people interested in modern IT solutions in the production industries.

Keywords: MCDA, DEMATEL, ERP, cloud system, Industry 4.0 